\title{
CONSTRUÇÃO DO CONHECIMENTO HISTÓRICO NA ESCOLA
}

\author{
HISTORIC KNOWLEDGE CONSTRUCTION AT SCHOOL
}

Matheus Mendanha Cruz ${ }^{1}$

\begin{abstract}
RESUMO: Este trabalho tem por objetivo apresentar o projeto que foi aplicado no início do ano letivo de 2016, em uma escola particular de Ponta Grossa. O projeto ressalta a discussão sobre a importância da História para a orientação da vida prática dos alunos: como a disciplina escolar pode oferecer suporte para a vivência da democracia e da realidade cotidiana de debates e bombardeios de informações. Para isso, oferecemos aos estudantes do sexto ano a oportunidade de escreverem a História da própria instituição de ensino a qual pertencem, possibilitando, assim, que percebessem a operação historiográfica e também exercessem a retirada de informações de vários documentos, gerando um olhar aguçado para a crítica de fontes, permitindo a autonomia no processo de formação de conhecimento.
\end{abstract}

Palavras-Chave: Ensino de história; Função da história escolar; Construção do conhecimento histórico.

\begin{abstract}
This paper aims to show the project conducted in the begin of 2016 school year, in a private school in Ponta Grossa. The project highlights the discussion about the importance of History to guide the students' practical life, how the subject can offer support to the experience of democracy and to the everyday reality of debates and flood of information. For this purpose, we offered the students from sixth grade the oportunity to write, by themselves, the history of the institution where they study, enabling them to understand the historiografic operation and exercise the withidrawal of information from several sources, generating a sharp eye to analyze the sources, allowing the authonomy in the process of constructing knowlede.
\end{abstract}

Keywords: History teaching; Function of History at school; construction of historical knowledge.

\section{Introdução}

Estar dentro de sala de aula e se deparar com a defasagem de leitura que há nos alunos, infelizmente não tem sido mais visto com espanto por alguns professores, pelo contrário, após o espanto sempre vem o consolo

\footnotetext{
* Esse texto foi escrito no ano de 2015 , durante o processo de formação na graduação do autor.

1 Bolsista CAPES; mestrando em História pela Universidade Estadual de Ponta Grossa UEPG; professor efetivo da Educação Básica do estado de Santa Catarina; membro do Grupo de Estudos em Didática da História - GEDHI.
} 
do "é assim mesmo". Tem se tornado rotina em algumas turmas a constante pergunta: "O que é pra fazer, professor?", embora os enunciados estejam claros a sua frente, quando não simplesmente respondem algo que imaginam, pois não leram de forma atenciosa e/ou crítica o que está sendo pedido.

A preocupação com esse tipo de realidade nos leva a questionar ainda se esses alunos estão saindo da Educação Básica com as ferramentas necessárias para a vivência num mundo onde a leitura é tão importante, e não apenas a leitura de decodificar as palavras, mas de interpretar, compreender e ler nas entrelinhas. Paulo Freire (1989) vai mais longe e ressalta a ideia de Leitura de Mundo, ou seja, saber captar o mundo ao redor, compreendê-lo, para poder colocar-se como sujeito da sua própria História.

Baseado nessas reflexões iniciais, o trabalho, a seguir, teve sua origem. A ideia, aqui discutida, refere-se à importância de uma Educação que leve mais além do que simplesmente decodificar letras e operar números; por uma Educação que não apenas mantenha os jargões, advindos da época da redemocratização, como ensino para a Democracia, para a Cidadania, mas transforme-os em realidade; que gerar alunos críticos possa ser uma construção cotidiana e não apenas um convencimento desses estudantes de determinadas ideias, mas a possibilidade de que eles construam, independentemente dos professores, suas posições quanto ao mundo que os cerca e o cotidiano que os devora sem ao menos permitir que estejam completamente preparados para a batalha que denominamos vida. Batalha esta que é regada com bombardeios de informações cotidianas. Nesse sentido, é preciso que munamos os educandos de maneira a saberem se defender e interpretar essas variadas informações que Ihes chegam às mãos, a ponto de serem sujeitos destas e terem autonomia em sua caminhada dentro da sociedade.

Isto posto, destaca-se que o presente artigo é baseado em um projeto pensado e desempenhado dentro do contexto de uma pequena escola particular da cidade de Ponta Grossa. Esta escola foi escolhida por já 
trabalharmos nela, o que facilitou o desenvolvimento do projeto dentro da continuidade das atividades pedagógicas frente à disciplina História. Afinal, a ideia é que a inserção das atividades e projetos, como o aqui exemplificado, não se dê apenas por intermédio de intervenções alienígenas ao cotidiano escolar, como se só fora do dia-a-dia da escola se possa ter práticas pedagógicas diferenciadas e criativas.

O trabalho a seguir estará disposto em divisões menores para melhor compreensão dos conceitos e ações. Começaremos por discutir a função da Educação e notar a importância desta preocupação; ainda debateremos a responsabilidade da disciplina História dentro da função social que a Educação Formal mantém e como alcançar o êxito dessas funções; por fim, relataremos e discutiremos alguns pontos do projeto e como esse pode auxiliar o cumprimento do papel da disciplina História dentro da realidade educacional que a escola está inserida.

\section{Função da Educação}

Não é possível pensar o ato educativo sem pensar qual a função que empregamos nele. Maria Nidelcoff (1980, p. 21) vai além e deixa claro que "se não possuímos objetivos claros, não somos educadores". Ter um norte, um objetivo, é fundamental para a construção da Educação, do contrário apenas haverá, cotidianamente, aulas e mais aulas, de modo superficial, sem cumprir propósito algum.

Freire (2002, p. 55) destaca que "onde há vida, há inacabamento", ou seja, o ato de educar é uma constante, mudar é uma constante, construir é uma constante. Compreender esse processo nos leva a perceber o nosso próprio inacabamento como educadores, deste modo gerando a humildade de ensinar aprendendo, despindo-nos de toda a proteção que o conhecimento acadêmico pode gerar e nos abrindo à construção diária do conhecimento. Mais especificamente dentro da área de História, Cerri (2011a, p. 74-75) aborda essa ideia, esclarecendo-a quando ressalta a importância do diálogo para a Educação e define que, para isso, é preciso 
"despir-se de preconceitos constantes, sobretudo o preconceito de que a ciência da história pode oferecer o rumo correto da história e o lugar certo do interesse dos povos". Temos a consciência de que é muitíssimo difícil abrir mão desta defesa, mas é necessário encarar essa abertura como um processo, um caminho que possibilite uma Educação capaz de munir os educandos para a vida cotidiana.

Ainda Freire (2002, p. 77) destaca que "aprender [...] é construir, reconstruir, constatar para mudar, o que não se faz sem abertura ao risco e à aventura do espírito" e é isso que deve ser a consciência do educador, esse senso de processo e de construção, construção esta que vai para muito além dos conteúdos programados para a sala de aula.

Os teóricos que trabalham a noção de Currículo afirmam que:

O currículo é um projecto, cuja elaboração, gestão e
avaliação engloba propósitos, pois a educação jamais pode
deixar de ser uma acto intencional e deliberado, com
processos de decisão partilhados e com práticas
interrelacionadas. Currículo [...] é um projecto social e
cultural, historicamente construído, decidido em função de
uma organização, geralmente escolar, que estabelece uma
fronteira de competências entre uma autoridade
administrativa, a da administração central, e uma autoridade
profissional, exercida por professores e outros actores no
contexto das escolas (PACHECO, 2007, p. 81).

Por mais que o currículo tenha indicações também daquilo que a própria sociedade espera, ou deveria esperar, para a sua Educação, é aquilo que se chama Currículo Oculto (tudo que é ensinado de maneira indireta, fora do conteúdo em si) que complementa esse processo educativo. Inclusive, Pardal (2005, p. 17) esclarece a função do Currículo Oculto da seguinte maneira: "o currículo oculto apoia, embora de maneira mais silenciosa que o formal, o sistema escolar enquanto instituição e, através deste, o sistema social que o suporta".

Ainda sobre objetivo para a Educação, Jean-Claude Forquin (1993, p. 125) estabelece-o afirmando que "a educação deve ter por meta essencial reforçar em cada indivíduo o ser social, o membro de uma coletividade bem definida no tempo e no espaço, e caracterizada por orientações culturais 
específicas" e esse objetivo só pode ser alcançado graças à preparação e à vivência, não simplesmente pelo caminho do conteudismo, mas através da junção dos conteúdos à expansão da participação do aluno dentro da própria estrutura da escola (Grêmios, representação discente).

Embora o conteudismo exacerbado, na perspectiva aqui defendida, não seja o ideal saudável para a Educação, é indispensável que o conteúdo seja também ensinado aos alunos. Vivemos em uma sociedade em que a Educação, infelizmente, tem visado muito o vestibular, e se a Educação Básica não fornecer nem ferramentas para a vivência cidadã na comunidade em que o educando está inserido e também não muni-lo para o vestibular, ela seria fracasso total.

$\mathrm{Na}$ realidade, pensar o resultado do processo como a construção de um cidadão não exclui a ideia de que a escola ainda é, ou deveria ser, detentora (não a única) da função de transmitir conhecimento científico e sistematizado também. É preciso que todo o processo educacional objetive o ensino do conteúdo através da construção de conhecimento para autonomia.

Devemos partir do contexto do aluno, mas a Educação deve levar o educando além, dar-lhe a possibilidade de escolher ampliar as suas fronteiras e experimentar realidades diferentes da sua atual ou de permanecer onde está, afinal, não é função da instituição escolar escolher o futuro dos educandos. Perceber a condição de sujeito no educando é a base para um educador consciente, do contrário a escola continuará a impor conceitos, ideias e padrões, ao invés de construí-los junto com o aluno. É complexo demais manter um ensino que sirva tanto para ensinar como viver em sociedade, e também para preparar o aluno que quiser seguir carreiras acadêmicas, ou técnicas, mas é preciso.

Jaime Pinsky e Carla Pinsky (2005), ressaltam a necessidade de uma História que aborde o conteúdo, mas não deixe de lado o desenvolvimento político-social dos educandos. Eles ressaltam que "é preciso, nesse momento, mostrar que é possível desenvolver uma prática de ensino de História adequada aos novos tempos (e alunos): rica de conteúdo, 
socialmente responsável e sem ingenuidade ou nostalgia" (PINSKY; PINSKY, 2005, p. 19)

A consciência de que é preciso sempre haver reflexão sobre a nossa prática pedagógica, é o repensar que gera os indicadores daquilo que devemos manter como prática educacional e o que devemos modificar, até mesmo deixar de usar em alguns casos (FREIRE, 2002, p. 24). Entretanto, para cumprir essa tarefa, é preciso que o professor esteja em formação contínua, estudando e buscando excelência na sua prática. Do contrário, não há autoridade moral para que o mesmo cobre responsabilidade e dedicação dos seus alunos (FREIRE, 2002, p. 103). Educar é ser exemplo, é ir além da obrigação, é repensar, é criar, é amar acima de tudo, é sonhar.

Objetivar, como já vimos aqui, é essencial para o ato de educar. Sem objetivar, sonhar, planejar, é impossível educar. É pensando nisso e tendo por objetivo a construção de educandos para a vivência em sociedade, uma vivência que o possibilite autonomia frente às questões que podem lhe aparecer pelo caminho, que pensamos o presente trabalho.

\section{Ensino de História}

Alguns autores têm trabalhado com a própria História da disciplina História. São nomes como Circe Bittencourt (1993) Laville (1999), Marcos Silva e Selva Guimarães Fonseca (2010) entre outros, que em seus trabalhos mostram a importância do Ensino de História e como este dentro do contexto da escola se torna campo de luta.

É nessa caminhada da História como disciplina escolar que percebemos quão valorizada esta é, muitas vezes até mesmo supervalorizando as suas dimensões de formadora. Laville (1999) traz uma discussão importante sobre a área de influência da História escolar sobre os estudantes no aspecto da disciplina como formadora de opinião. Ele sentencia que 
[...] neste fim de século, é possível que a narrativa histórica não tenha mais tanto poder, que a família, o meio ao qual se pertence, circunstâncias marcantes no ambiente em que se vive, mas sobretudo os meios de comunicação, tenham muito mais influência (LAVILLE, 1999, p. 137).

Mas, de qualquer maneira, ainda podemos, através da História, ver como essa ciência é bastante visada para a construção da sociedade e da ética que esperamos que os jovens, na escola, possam desenvolver. Podemos notar isso dentro da própria Lei de Diretrizes e Bases (LDB) em vigência, que defende o ensino da matriz indígena e africana para além de unicamente a europeia.

A seção anterior do trabalho discutiu os objetivos que esperamos alcançar pelos meios educacionais, e pensar isso dentro da disciplina é fundamental para a reflexão acerca da prática educacional do professor de História. Percebemos o valor da disciplina de História para essa formação social dos nossos educandos, mesmo, como já destacado, não sendo a única responsável por tal.

Trabalhar História com responsabilidade e compromisso com os objetivos escolhidos e discutidos é ir muito além do que simplesmente a lógica conteudista, lógica esta que está envolta em datas e personagens heroicos importantes. A História para o tempo presente dever ser prática, embora muitos pensem que a ciência História seja apenas teórica.

Pensar a História como prática é pensá-la com ferramenta para construir a autonomia dos educandos, uma vez que, a partir dela, é possível ensinar a utilização e compreensão daquilo que está ao nosso redor. Sim, a História deve ser prática, uma disciplina que vise auxiliar a vivência cotidiana do educando.

A discussão sobre a praticidade da História passa pelos escritos de Rüsen (2010b, p. 32), que a defende como orientadora da vida, sendo esta a sua função cotidiana para o sujeito. Rüsen (2001, p. 10-11) explora o conceito de Consciência Histórica, que seria a responsável por organizar e dar sentido aos conhecimentos a respeito do passado e, através dessa 
gama de saberes, guia as decisões do presente e é a base para as projeções de futuro.

Rüsen (2010a, p. 45-46) também apresenta quatro modos de geração de sentido e Cerri (2011b, p. 100-103) os explora de maneira a deixar mais inteligível sua compreensão. Convém destacar que estes modos não são hierarquizáveis, pois no cotidiano acabamos por utilizar todos eles, mas o autor os separa para uma explicação didática. São eles: Tradicional; Exemplar; Crítico; Genético.

O modo tradicional acaba por naturalizar o presente como se 0 mesmo e o passado fossem apenas um. O modo exemplar se utiliza da História para consagrar vilões e heróis pelos quais organizam-se as bases morais de uma determinada sociedade. O modo crítico é baseado na desconstrução, contrapondo a verdade posta com uma verdade alternativa. Por fim, o modo genético que se refere a compreender a História como processo que permite o presente ser o que é.

Essa proposta de modos de geração de sentido possibilita a compreensão da dinâmica de pensamento, o que auxilia no processo de discussão de como o passado e a História, de forma específica, podem e auxiliam na compreensão do presente e na localização temporal do sujeito.

Outro pensador que também disserta sobre a função da História é Koselleck (2006), é dele a proposta do conceito de "Espaço de Experiência" e de "Horizonte de Expectativa". Dentro dessa teoria, a experiência é "o passado atual, aquele no qual acontecimentos foram incorporados e podem ser lembrados" (KOSELLECK, 2006, p. 309). Deste modo, cria-se um lastro de conhecimentos que conjugado, às vezes de modo involuntário, dão origem a conceitos interiorizados que originam as estruturas que balizam as ações do sujeito e o fazem trazer o futuro para o presente, que seria o "Horizonte de Expectativa" (KOSELLECK, 2006, p. 310).

É baseado nestes conceitos que propusemos o projeto que deu origem a este texto. Educar é saber ouvir e Paulo Freire (2002, p. 128) nos ensina isso quando afirma que "o Educador que escuta aprende a difícil lição de transformar o seu discurso, às vezes necessário, ao aluno, em uma fala 
com ele" e também, nesse mesmo trecho, que o ato de educar é a ação de construção, afinal "toda prática educativa demanda a existência de sujeitos, um que, ensinando, aprende, outro que, aprendendo, ensina" (FREIRE, 2002, p. 77).

Como uma das principais pontes a ser edificada para se alcançar esse diálogo entre educador e educando, visando sempre a construção de um conhecimento para a vivência autônoma no cotidiano, podemos apontar a utilização das fontes em sala de aula.

\section{A Fonte na Sala de Aula}

A ideia de colocar a fonte histórica dentro de sala de aula não é nova (CAIMI, 2008, p. 133). Se olharmos para a grande maioria dos livros didáticos, podemos notar que há tempo as fontes aparecem, entretanto a sua utilização no ato pedagógico deve ser objeto de reflexão. Nesse sentido, propomos, nas próximas linhas deste texto, explanar sobre a utilização desse recurso didático no cotidiano da sala de aula.

Num primeiro momento, é importante destacarmos que trabalhar com fontes históricas em sala de aula não é pretender fazer do educando do Ensino Básico um historiador em miniatura. Essa preocupação precisa ser pontuada aqui, afinal o objetivo da Educação Básica no Brasil é a construção do cidadão, logo o foco tem que ser munir o educando de ferramentas possíveis para ser um cidadão participativo.

Abordar fontes históricas em sala de aula, não apenas apresentá-las aos alunos como exemplos, alegorias frente a dado conteúdo. É importante que o estudante tenha a noção da História como processo, desconstruindo, desse modo, a História Tradicional marcada por heróis e datas. Entender a construção da sociedade atual é apreender conceitos que estão além de nomes e números, é adquirir a habilidade de interpretação frente a uma dada realidade. 
Selva Fonseca nos esclarece sobre o Ensino de História, afirmando que a aquisição do conhecimento histórico está muito mais além da sala de aula:

A formação do aluno/cidadão se inicia e se processa ao longo de sua vida nos diversos espaços de vivência [...] todas as linguagens, todos os veículos e materiais, frutos de múltiplas experiências culturais, contribuem com a produção/difusão de saberes históricos, responsáveis pela formação do pensamento, tais como os meios de comunicação de massa rádio, TV, imprensa em geral -, literatura, cinema, tradição oral, monumentos, museus, etc. (FONSECA, 2003, p. 164)

É também importante pensarmos na variedade de fontes que estão disponíveis para a construção do conhecimento histórico escolar, ressaltando que "o trabalho com diferentes fontes é sempre indispensável, pois o entendimento de uma realidade não se faz a partir de um documento isolado, embora a reflexão possa se iniciar a partir de um único documento" (CABRINI; CIAMPI; VIEIRA; PEIXOTO; BORGES, 2000, p. 60).

Se pensarmos a Educação Básica como um todo, perceberemos que, através do ensino do conteúdo, às vezes apenas erudito, de História, temos a possibilidade de auxiliar o educando no manuseio de ferramentas de interpretação de uma dada realidade, sempre partindo de questões que são postas no presente e tem ligação com a realidade que o jovem está inserido. A História precisa ser construída como conhecimento com função social, precisa ser orientadora da vida e, através do conhecimento científico, fomentadora de modificações na sociedade de modo consciente.

Essa é a importância da abordagem empregada à construção de conhecimento baseado em fontes históricas. O saber escolar histórico deve utilizar o questionamento para a construção do conhecimento, ou seja, é preciso que haja uma pergunta a ser respondida a fim de que no caminho percorrido para a resposta possa haver a elaboração de conhecimento útil aos envolvidos. Alguns autores explicam que "ao trabalhar em classe o documento, o aluno irá perceber que o documento fala e que o faz tanto melhor conforme as perguntas que se Ihe colocam" (CABRINI; CIAMPI; 
VIEIRA; PEIXOTO; BORGES, 2000, p. 60) e o estudante só perceberá isto se for lhe dada a oportunidade de dialogar com o documento.

Quando colocamos a fonte em primeiro lugar, damos a oportunidade ao aluno de questioná-la e, a partir daí, valorizar o saber histórico. Trabalhar com temas da atualidade para fazer a ligação com o passado é uma das possibilidades, mas também é possível que o professor selecione a fonte e leve para a sala de aula com o intuito que os alunos possam desconstruí-la, e é esse processo que propiciará ao educando a compreensão de como se portar frente às informações que nos bombardeiam no cotidiano.

A desconstrução da fonte em conjunto na sala de aula possibilita a compreensão da História como processo e criação datada e construída para e por alguém. Essa prática oferece ao educando a base para a prática de Leitura de Mundo, defendida por Paulo Freire (1989). Mas não podemos nos acomodar apenas em descontruir realidades, precisamos reconstruí-la.

A reconstrução da fonte e do seu contexto possibilitará o ensino do conteúdo em si e também fará que o educando se perceba como sujeito e construtor da própria História. Essa etapa oferece ao aluno a oportunidade de, junto ao professor, construir o conhecimento escolar e notar o que Certeau (2000, p. 66) denomina de Operação Historiográfica. Perrenoud (1998), em seu texto, também defende esse processo de desconstrução de um saber dado e a reconstrução de uma saber efetivamente escolar, o que torna o aluno sujeito construtor do seu próprio saber.

É nessa etapa de reconstrução que a crítica feita anteriormente frente às fontes deve se converter em produção. Aqui se dará, como já afirmado, o ensino do conteúdo em si, mas também permitirá a desenvolvimento de várias habilidades que a construção do conhecimento possibilita, como leitura, interpretação, redação, oratória, dentre outras. Como o processo de ensino e aprendizagem partiu de um questionamento fomentado pelo professor, mas oriundo dos estudantes, estes se veem interessados na construção do saber e tendem a apreender melhor os conteúdos e conceitos referentes ao assunto abordado, afinal veem, naquele tema, importância e 
utilidade para a sua vida prática, deste modo enxergando-se como sujeito histórico e levando a História a cumprir seu papel de orientadora da prática cotidiana da vida.

Esse processo de desconstrução/reconstrução permite a desnaturalização do conhecimento histórico, a não-entrega feita pelo professor do conteúdo pronto e intocável. Selva Fonseca (2003, p. 90) destaca como problemas deste modelo de ensino simplificador: "a exclusão e a simplificação do conhecimento histórico escolar introjetam nos alunos a seguinte ideia: vocês não fazem história, nós não fazemos história. A história é feita por e para alguns, que não somos nós, são outros e são poucos".

Para que haja a reconstrução que aqui temos tratado, é preciso ânimo e coragem do professor, afinal "o professor é o profissional que domina não apenas os métodos de construção do conhecimento, mas um conjunto de saberes que possibilita sua socialização e a sua reconstrução no processo de ensino e aprendizagem" (FONSECA, 2003, p. 102).

Entretanto, para que isso ocorra, o professor deve ressaltar o papel de sujeito dos educandos, como Freire (2002, p. 29) afirma ao destacar que "nas condições de verdadeira aprendizagem, os educando vão se transformando em reais sujeitos de construção e da reconstrução do saber ensinado, ao lado do educador, igualmente sujeito do processo".

No processo de ensino saudável, tanto o professor quanto o educando têm sua função. Podemos até mesmo chamar esse relacionamento professor-aluno na construção do conhecimento de dialético, pois é essa a lógica de uma aula baseada no diálogo, do processo formador que enxerga mestres e alunos como uma equipe que busca, juntos, aprender e também ensinar-se.

Gerar praticidade para o conhecimento histórico é fundamental. É necessário que nós, como educadores na área de História, estejamos alinhados com objetivos que levem aos educandos a ideia de História para a própria vida, não como algo puramente abstrato, maçante e teórico. Carla Pinsky e Jaime Pinsky (2005, p. 28) também acreditam que "quanto mais o 
aluno sentir a História como algo próximo dele, mais terá vontade de interagir com ela, não como uma coisa externa, distante, mas como uma prática que ele sentirá qualificado e inclinado a exercer".

Toda a problematização em cima dos documentos permite uma diferenciação grande quanto aos alunos que não tem acesso a esse tipo de método, uma vez que:

O cenário da escola não problematizadora favorece que o ensino de História pouco desperte o aluno para a apreensão do conhecimento, já que, para eles, este ensino não tem utilidade, além de propiciar uma visão que assume o passado como a única possibilidade de análise histórica (FERREIRA; COSTA, 2015, p. 20)

Cumprimos nossa função dentro dessa ideia quando o aluno consegue responder a seguinte pergunta: Para que serve a História? Inclusive nós, enquanto professores, devemos sempre retornar a essa singela, mas importante pergunta. Paulo Freire (2002, p. 24) destaca que "a reflexão crítica sobre a prática se torna uma exigência da relação Teoria/Prática sem a qual a teoria pode ir virando blábláblá e a prática, ativismo", ou seja, se não estivermos sempre nos perguntando sobre aquilo que estamos fazendo acabamos seguindo em uma rotina que passa longe do ato de educar que, como já vimos anteriormente, é baseado no estabelecimento de objetivos.

\section{Construção do Conhecimento Histórico: A História da Escola}

Frente a todo o debate até aqui levantado queremos, nesse momento, partilhar uma prática que buscou oferecer aos educandos ferramentas para a sua leitura de mundo e atividade como cidadão, para além de conceber a atividade do historiador e perceber-se como sujeito da construção histórica.

Conhecer os alunos e compreender o seu contexto é parte fundamental para o ato educativo, do contrário não conseguiremos envolver 
os alunos nas problemáticas que podem ser apresentadas dentro da disciplina. Sendo assim, não permitimos a constituição de identidade do indivíduo como sujeito do próprio processo histórico.

O parágrafo anterior se apresenta como justificativa da escolha da escola para aplicação do projeto. A Instituição Escolar escolhida é uma pequena escola composta por uma classe média que está em ascensão, deste modo os alunos não são de uma elite que possamos chamar de clássica, mas têm acesso a meios de comunicação e de estudos que possibilitam desenvolvimento para além dos muros escolares.

Pensando nisso, o projeto ganha ainda mais importância em sua execução. Embora os alunos, em sua maioria, tenham acesso à internet e outros meios de comunicação, é preciso que se construa ferramentas para que este educando desenvolva a sua leitura do mundo, daquilo que está a sua frente. As atividades pensadas aqui foram desenvolvidas com o intuito de que os educandos tenham a autonomia de interpretação e busca de informações sobre assuntos de seus interesses, não ficando presos a interpretações ofertadas por terceiros.

Dentre tantos temas que poderiam ser escolhidos, foi concedida preferência à construção da História da própria escola porque é algo que, sem sombra de dúvidas, todos os educandos e professores têm em comum no seu cotidiano. Esse fator ganha maior envergadura porque muitos pais de alunos são ex-alunos, gerando, assim, uma empatia pelo desenvolvimento da escola, possibilitando a identificação com a própria História.

O projeto foi inserido dentro do conteúdo de Introdução ao Estudo de História, em que se aborda o conceito e a utilização de fontes históricas. Visamos, através das atividades, fomentar o diálogo entre o conteúdo programático e a vivência pessoal dos educandos, tornando possível a percepção dos mesmos como sujeitos e também da História como processo de construção e não algo dado e acabado.

As atividades foram projetadas para ocorrerem dentro das próprias aulas de História, dividindo-as da seguinte maneira: das três aulas 
semanais, uma seria destinada a elaboração e execução do projeto. O cronograma foi elaborado para que todas as atividades, desde a apresentação do projeto ao trabalho escrito final, fossem concluídas em três meses.

Ao propormos o projeto para a turma, houve adesão geral e empolgação. Foi deixado bem claro como se daria o processo de construção do trabalho, principalmente que eles seriam os grandes protagonistas porque escolheriam as fontes que utilizaríamos e quando as utilizaríamos. A orientação e supervisão do professor foi uma constante, mas houve liberdade para a construção e domínio do processo historiográfico.

Como primeira etapa do projeto, decidimos observar as fontes iconográficas. Para isso, a direção da escola cedeu várias fotos tiradas durante algumas atividades da instituição. Essas fotografias reportavam a vários momentos da História da escola no decorrer dos últimos vinte anos. Os alunos se deliciaram em observar as fotos e ver as modificações e permanências no prédio escolar e, também, nas atividades oferecidas pela escola. Foi orientado que observassem esse processo do tempo, e eles foram além, pois notaram, também, estilos de corte de cabelo, embalagens de refrigerantes, etc.

Durante todo o processo de análise de fontes, foi colocado para os alunos a importância de perguntar para o documento. Em todas as etapas da pesquisa essa prática foi reforçada com o intuito de perceberem que 0 discurso científico da História é baseado não em certezas, mas em perguntas.

Essa observação sobre as mudanças e permanências é fundamental, pois cria a percepção da diacronia, base para a compreensão da História como processo. Para esta etapa, foram utilizadas duas aulas, de maneira que na primeira os alunos selecionaram algumas fotos que julgaram interessantes e que ofereciam informações importantes, e na segunda, eles começaram a retirar as informações das imagens.

Na segunda etapa do processo de construção, utilizamos a fonte oral, inclusive a opção por esta fonte partiu absolutamente dos educandos, sem 
que houvesse a necessidade da intervenção/sugestão do professor. Eles escolheram fazer uma entrevista com a diretora e fundadora da escola sobre o início da instituição e algumas dúvidas e curiosidades que tinham. Foi separada uma aula para que, juntos, pensássemos as perguntas a serem feitas e outra aula para a entrevista ser realizada.

No momento da entrevista, os alunos se envolveram de fato com as perguntas e as histórias que a diretora contava sobre o desenvolvimento físico do prédio que abriga a instituição e curiosidades sobre ex-alunos, dentre outras vivências.

A etapa três foi externa à escola. Levamos os alunos ao Museu Campos Gerais, que também mantém um acervo de arquivo, e os educandos tiveram a possibilidade de fazer o trabalho com as fontes escritas/impressas. Foi decidido sobre a importância do contexto em que a escola surgiu e, para a compreensão de tal, utilizamos jornais antigos de 1983 e 1998, pois foram os anos, respectivamente, de fundação e de acerto da documentação da escola.

Durante esta etapa, foi interessante observar como os alunos se envolviam observando as empresas que ainda estão atuando em Ponta Grossa, a localidade das mesmas, os costumes que eram divulgados e assim por diante, gerando um maior sentimento de pertencimento à cidade, já que a familiaridade com os nomes, comércios, indústrias, etc, Ihes era empolgante. O trabalho desta etapa foi bem-sucedido, uma vez que visava à compreensão dos estudantes das atividades do pesquisador e do ambiente em que esse processo se dá.

Para a finalização do trabalho com a parte escrita, foi conversado com a professora de Português e ela aceitou, prontamente, participar do projeto auxiliando em técnicas de redação, deste modo levando o projeto a cumprir a Operação Histográfica (CERTEAU, 2000) com a escrita.

Ocorreram alguns desencontros após essa etapa do projeto, o que fatalmente impediu a sua continuidade. Entretanto, os alunos chegaram a produzir uma primeira versão do texto referente à História da escola. Embora não tenhamos a redação final em mãos, foi alcançado o objetivo de 
apresentar para os alunos a Operação Historiográfica (CERTEAU, 2000), 0 que é conteúdo de Introdução ao Ensino de História, programado para o início do sexto ano. É este processo que possibilita a leitura de mundo, gerando as perguntas-chave para o processo de apreensão do entorno e do cotidiano. A atividade de construção da História demonstra, claramente, o quanto é importante $e$ instigante se perguntar sobre o presente $e$ retroceder ao passado como meio de compreendê-lo, afinal a História tem como função "a orientação da vida" (RÜSEN, 2010b, p. 32) e isto só se faz de modo subjetivo.

Pensar o educando como um todo é importante, por isso a prática educativa deve possibilitar o seu desenvolvimento de modo completo. 0 projeto aqui apresentado visou construir, para além do conhecimento histórico que, no caso presente, é a apreensão do conceito de fonte histórica, a percepção da História como processo. Além disto, atingimos também o desenvolvimento da leitura, interpretação e da autonomia para a retirada de informações frente ao contexto social que o educando está inserido.

\section{Conclusões}

Apreensão de conteúdos é muito mais do que decorar frases prontas e repeti-las no momento da avaliação, inclusive esta deve ser encarada como um processo de verificação da aprendizagem e do ensino. O projeto, aqui abordado, visou dialogar com os conceitos que foram discutidos no início do texto, oferecendo aos educandos um processo educacional que rompa com as barreiras do conteudismo e possibilite a formação integral do estudante, visando, para além da aprendizagem do conteúdo, as ferramentas para uma leitura de mundo baseada em fatos e crítica aos mesmos e a autonomia para tal processo.

A prática pedagógica necessita ser cotidianamente refletida, pois educar é ter compromisso com o presente e o futuro dos nossos educandos. 
Se não houver essa consciência de compromisso não estamos educando. Precisamos apreender de fato, colocar em prática, pois a Educação é um processo que vai além dos livros didáticos e tem sua responsabilidade dentro da sociedade. Quando os educadores tiverem essa consciência e começarem a praticá-la teremos uma Educação responsável, um ensino que possibilitará a formação de cidadãos que participem ativamente das atividades das comunidades em que estão inseridos de maneira autônoma.

\section{Bibliografia}

BITTENCOURT, C. Os confrontos de uma disciplina escolar: da história sagrada à história profana. Revista Brasileira de História, São Paulo, v.13, n. 25/26, p.193-221, 1993.

CABRINI, C. ; CIAMPI, H. ; VIEIRA, M.; PEIXOTO, M. ; BORGES, V. P. Ensino de história: revisão urgente. São Paulo: EDUC, 2000.

CAIMI, F. E. Fontes históricas na sala de aula: uma possiblidade de produção do Conhecimento histórico escolar? Anos 90, Porto Alegre, v. 15, n. 28 , p. $129-150,2008$.

CERRI, L. Cartografias temporais: metodologias de pesquisa da consciência histórica. Educação e Realidade, Porto Alegre, v. 36, n. 1, p. 59-81, 2011 a.

CERRI, L. F. Ensino de história e consciência histórica. Rio de Janeiro: FGV, 2011b.

CERTEAU, M. A escrita da história. 2. ed. Rio de Janeiro: Forense Universitária, 2000.

FERREIRA, C. A.; COSTA, M. A. Ensino, história e educação com/sem convergência. História \& Ensino, Londrina, v.21, n. 2, p. 13-30, 2015.

FONSECA, S. G. Didática e prática de ensino de história: experiências, reflexões e aprendizados. Campinas: Editora Papirus, 2003. (Coleção Magistério: Formação e Trabalho Pedagógico).

FORQUIN, J.-C. Escola e cultura: as bases sociais e epistemológicas do conhecimento escolar. Porto Alegre: Artes Médicas Sul, 1993.

FREIRE, P. A importância do ato de ler: em três artigos que se completam. São Paulo: Autores Associados : Cortez, 1989. (Coleção Polêmicas do Nosso Tempo, v. 4). 
FREIRE, P. Pedagogia da autonomia: saberes necessários à prática educativa. 24. ed. São Paulo: Paz e Terra, 2002. (Coleção Leitura).

KOSELLECK, R. Espaço de experiência e horizonte de expectativa. In: KOSELLECK, R. Futuro passado: contribuição à semântica dos tempos históricos. Rio de Janeiro: Contraponto: Ed. PUC-Rio, 2006. p. 305-327.

LAVILLE, C. A guerra das narrativas: debates e ilusões em torno do ensino de história. Revista Brasileira de História, São Paulo, v. 19, n. 38, p. 125$138,1999$.

NIDELCOFF, M. T. Uma escola para o povo. 30. ed. Tradução de J. S. TREVISAN. São Paulo: Editora Brasiliense, 1980.

PACHECO, J. A. Currículo, investigação e mudança. In: LIMA, L. C. et al. (org.). A educação em portugal (1986-2006). Lisboa: Sociedade Portuguesa de Ciências da Educação, 2007. p. 80-148.

PARDAL, L. A. A escola, o currículo e o professor. 2. ed. Aveiro: Aveiro Universidade, 2005.

PERRENOUD, P. La transposition didactique à partir de pratiques: des savoirs aux compétences. Revue des Sciences de l'Éducation, Montréal, v. 24, n. 3, p. 487-514, 1998.

PINSKY, J.; PINSKY, C. B. Por uma história prazerosa e consequente. In: KARNAL, L. (org.). História na sala de aula: conceitos, práticas e propostas. 3. ed. São Paulo: Contexto, 2005. p. 17-36.

RÜSEN, J. Perda de sentido e construção de sentido no pensamento histórico na virada do milênio. História: Debates e Tendência, Passo Fundo, v. 2, p. 9-22, dez. 2001.

RÜSEN, J. Aprendizado histórico. In: SCHIMIDT, M. A.; BARCA, I.; MARTINS, E. R. Jörn Rüsen e o ensino da história. Curitiba: UFPR, 2010a. p. 41-49.

RÜSEN, J. História viva: teoria da história: formas e funções do conhecimento histórico. Brasília: UnB, 2010b.

SILVA, M. A.; FONSECA, S. G. Ensino de história hoje: errâncias, conquistas e perdas. Revista Brasileira de História, São Paulo, v. 31, n. 60, p. 13-33, 2010. 
Recebido em 12 de outubro de 2016 Aceito em 07 de outubro de 2019 